\title{
Experimental Analysis of Factors Affecting the Power Output of the PV Module
}

\author{
Arjyadhara Pradhan ${ }^{1}$, Bhagbat Panda ${ }^{2}$ \\ School of Electrical Engineeing, Kalinga Institute of Industrial Technology (KIIT) University, India
}

\begin{tabular}{|c|c|}
\hline Article Info & ABSTRACT \\
\hline Article history: & \multirow{10}{*}{$\begin{array}{l}\text { Energy is the driving force in all the sectors as it acts like an index of } \\
\text { standard of living or prosperity of the people of the country. However heavy } \\
\text { dependence on fossil fuels leads to global warming, hence there is a need for } \\
\text { the use of clean, sustainable, and eco friendly form of energy. Among the } \\
\text { various types of non-conventional energy solar energy is the fundamental as } \\
\text { it is abundant, pollution free and universally available.Even though the main } \\
\text { input to the PV system is the solar radiation still there are other factors which } \\
\text { affects the efficiency of the pv module. In this paper real time experiment has } \\
\text { been conducted to analyze the effect of various factors like irradiance, } \\
\text { temperature, and angle of tilt, soiling, shading on the power output of the pv } \\
\text { module. Temperature is a negative factor which reduces the efficiency of the } \\
\text { module and can be reduced by various cooling arrangements. Presence of } \\
\text { dust particles and shading obstructs the incident solar radiations entering the } \\
\text { panel and the effect is seen in the iv and pv curve .For better performance } \\
\text { solar tracking at maximum power point is suggested to improve the power } \\
\text { output of the pv module. }\end{array}$} \\
\hline Received Mar 22, 2017 & \\
\hline Revised May 13, 2017 & \\
\hline Accepted Jun 3, 2017 & \\
\hline Keyword: & \\
\hline Irradiance & \\
\hline Tracking & \\
\hline Fillfactor & \\
\hline Soiling & \\
\hline Shading & \\
\hline
\end{tabular}

Copyright @ 2017 Institute of Advanced Engineering and Science. All rights reserved.

\section{Corresponding Author:}

Arjyadhara Pradhan,

School of Electrical Engineering,

KIIT University,

Campus 3, kiit road, patia-751024, Bhubaneshwar, Odisha, India.

Email: aryaa.dharaa@yahoo.com

\section{INTRODUCTION}

Solar energy is a very attractive renewable energy source due its various advantages. Light weight, free, sustainable, less complex structural requirement, noise free operation, absence of large rotating machinery, easy installation, application close to requirement, less maintenance are some of its advantageous features for gaining attention in the energy sector in comparison to fossil fuels. The consumption of fossil fuels causes climatic changes due to the release of carbon-dioxide to the atmosphere. An array of solar panels makes photovoltaic system which converts solar radiation into electricity. Each panel is made of modules and each module are made of solar cells which are mostly semiconductors. Fill factor and efficiency are the estimating factor for knowing the capacity of the pv cell. Studies shows that only a fraction of solar light striking the module is converted into electrical energy and the rest of the absorbed energy is converted to heat which cause increase in the junction temperature [1]. El Hadi Chahid studies the influence of various factors on the iv characteristics of pv cell. These are like number of measurements taken, cell voltage range, series, parallel and hybrid combination. He used Newton Raphson method to calculate the parameters and compared it with the manufacturer data sheet [2].

It is seen that pv module efficiency decreases with increase in temperature [3].The cells will also exhibit long-term degradation if the temperature exceeds a certain limit [4]. The cell efficiency is known to decrease due to non uniform temperatures across the cell [5],[6]. Solar tracking is also an efficient way of improving the efficiency of the module. Load matching is required for extracting maximum power from a pv 
module. There are two ways of tracking passive tracking where the module orientation changes slowly as per the set path and active tracking which is based on the use of optical sensors. As stated by Mousazadeh et al. [7], the use of sun-trackers cause an increase in the energy collected from sun by $10 \%$ to $100 \%$ which depends on geographical conditions and time period. Recently a 45-day experimental study conducted by researchers concludes the fact that by the use of sun-trackers, the amount of energy produced significantly increases by 14-20\% [8]. The same results were obtained by Eke and Senturk and their results demonstrated than after one year of operation, about $30 \%$ more energy is obtained by a dual-axis sun tracking system than the latitude-tilt fixed system [9]. Dust deposition on the surface of solar modules can cause two different effects i.e. firstly by reducing the amount of solar radiation by decreasing the transmittance of the glass cover and secondly by reducing the concentrating ability of the concentrating optical system [10]-[12]. Dust deposition depends on various factors like material, size, wind speed, humidity, tilt, geographical location, seasonal effect etc [13]-[16]. In a partially shadowed cell the shadowed portion does not produce any electrical power where as the unshaded part produces power. The voltage generated from the illuminated part forward bias the parallel rectifier. As the shadowed area is small a large circulating current flows which causes excessive heating. Thus the damage caused by shadowing can be reduced by using bypass diode. The bypass diode provides an alternative path for the load current and hence the damage can be reduced. Even due to shading effect multiple maximum power points exist on the PV curve [17]. Thus the pv user generally wants the pv system to operate at its highest energy conversion output by operating at maximum power point irrespective of any environmental changes [18].

\section{FACTORS AFFECTING THE OUTPUT PERFORMANCE OF THE PV MODULE}

Studies show that that there are several factors which affect the power output of pv module. While designing a PV system these factors should be given importance for better performance. The analysis was carried out in real time basis on the month of March in the terrace of campus 3 block A, school of electrical engineering KIIT University, Bhubaneswar, India. A 37 watt Photovoltaic module of make Vikram Solar was used for the experiment purpose. The module specification is given as below. A solar meter was used to measure the irradiance level. Resistance temperature detector was used to measure the temperature of the pv module. A voltmeter and ammeter of dc type was used for measurement of voltage and current. A rheostat was connected for varying the resistance which acts like a load. For the soiling and shading test two nos of pv modules of same rating was used so that the output of dusty panel was compared with that of the clean panel and unshaded panel with shaded one..The output characteristics of solar cells are expressed in the form of I-V curve and P-V curve. The module specification is given as below.

Table 1. Specification of the Photovoltaic Module

\begin{tabular}{cc}
\hline Parameter & Specification \\
\hline Maximum power & 37 watt \\
Open circuit voltage & 21.8 volt \\
Short circuit current & $2.40 \mathrm{amp}$ \\
Maximum Voltage & $17.20 \mathrm{volt}$ \\
Maximum Current & $2.20 \mathrm{ampere}$ \\
Area & $0.367 \mathrm{~m}^{2}$ \\
Length & $66.5 \mathrm{~cm}$ \\
Width & $55.2 \mathrm{~cm}$ \\
\hline
\end{tabular}

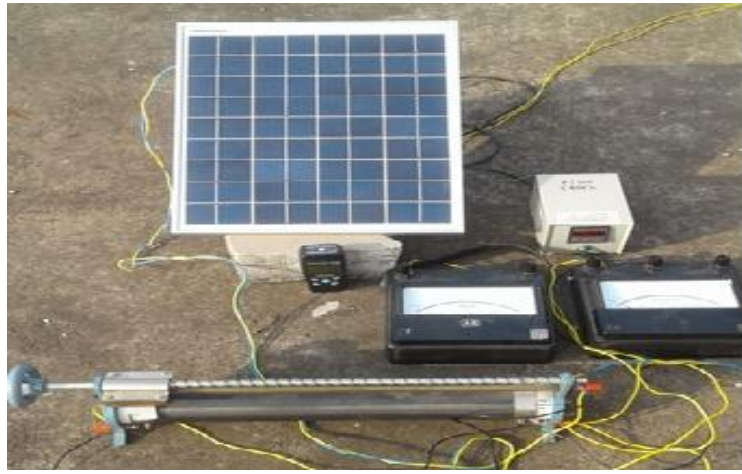

Figure 1. Real time experimental setup for the analysis of various factors affecting pv module performance 


\section{RESULTS AND ANALYSIS}

In this experimental analysis various factors like irradiance, temperature, angle of tilt, soiling and shading are taken to see the effect of these various factors on the power output of the pv module.

\subsection{Effect of Irradiance}

As the Sun's position changes throughout the day irradiance also keeps changing with it. It is found that maximum irradiance is around 12:00 to 1:00 pm and slowly it goes on decreasing. Keeping factors like temperature and spectral content constant both short circuit current and open circuit voltage increases with increase in the intensity of radiation. As the no of photons striking the module increases photon generated current also increases.

Table 2. Values of Maximum power and Irradiance at regular time interval

\begin{tabular}{ccc}
\hline Time in hours & $\begin{array}{c}\text { Irradiance } \\
\left(\text { watt } / \mathrm{m}^{2}\right)\end{array}$ & $\begin{array}{c}\text { Maximum } \\
\text { Power (Watt) }\end{array}$ \\
\hline 10:00-11:00 & 700 & 14.4 \\
11:00-12:00 & 800 & 15.8 \\
12:00-13:00 & 842 & 16.4 \\
13:00-14:00 & 756 & 15.4 \\
14:00-15:00 & 584 & 11.6 \\
15:00-16:00 & 352 & 6.4 \\
\hline
\end{tabular}

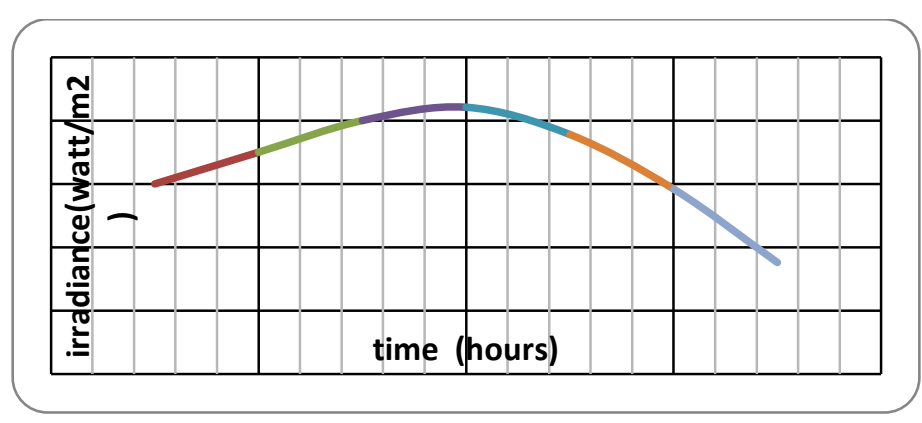

Figure 2. Shows the variation of solar irradiance with time of the day

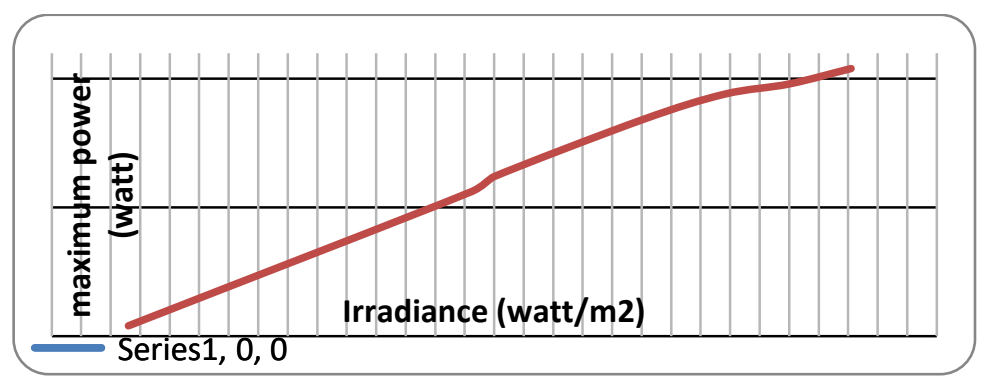

Figure 3. Shows maximum power increase with increase in irradiance

From the real time experiment conducted from morning 10 am to $4 \mathrm{pm}$ it was found that during the early hours the value of solar irradiance was less where as it reached its peak at around 12:00 to 1:00pm and again with the sun's position the value decreased. Maximum power calculated was also found to increase with the increase in solar irradiance.

\subsection{Effect of Temperature}

With the increase in solar insolation photon generation rate increases as there is a reduction in the band gap. The total numbers of photons striking the module are not fully converted to electrical energy rather some amount of it is converted to heat thereby causing a rise in the temperature of the module. It is also found that short circuit current decreases slightly where as there is a remarkable reduction in open circuit 
voltage. Even temperature rise causes increase in reverse saturation current and decrease in Fill factor. Literature studies show that with the increase of $1 \mathrm{~K}$ reduces photoelectric conversion efficiency by $0.2 \%$ to $0.5 \%$. M.Mohamed Musthafa in his work stated that the temperature rises to maximum 39.6 degree while conducting an experiment from morning 8 am to 4 pm [10].

From the experiment, Figure 4 it was found that there is a difference in temperature for the module back surface and front surface of the module. Front surface is having higher temperature then that of the back surface. Table 3 shows a reduction in efficiency with increase in temperature. Even though at 12:00-1:00 pm the sun is at its maximum position and the irradiance level is high but due to the temperature effect the efficiency decreases by $0.56 \%$ for every degree centigrade rise in temperature. Hence cooling of modules are highly recommended to increase the efficiency. It is also observed that further decrease in temperature towards the end of the day doesnot increase the efficiency as the level of irradiance also goes down. By using either water cooling or forced air cooling the temperature of the module can be reduced at regularly intervals so that the system can be made to operate at the maximum allowable value causing less loss.

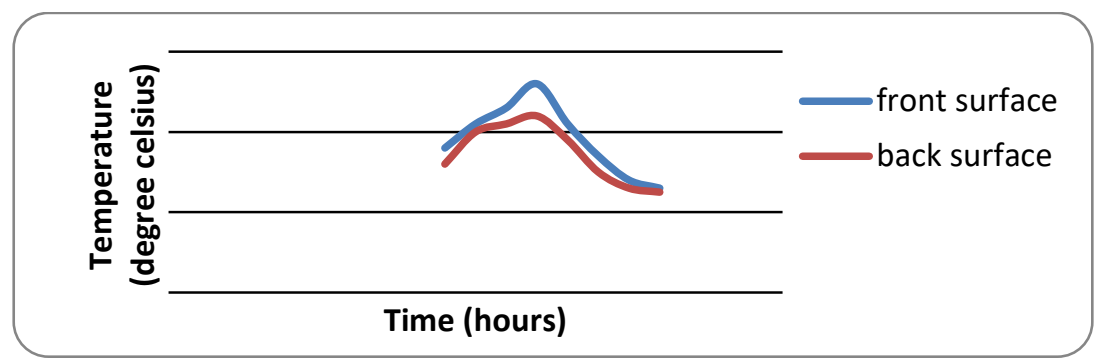

Figure 4. Shows the temperature of the module at both the surfaces

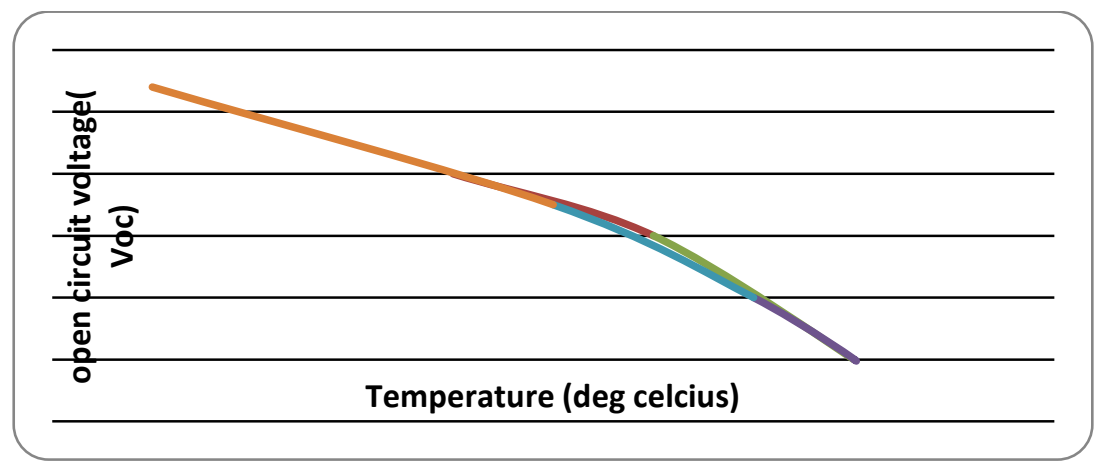

Figure 5. Shows the variation of open circuit voltage with temperature

Table 3. Efficiency at various temperatures

\begin{tabular}{ccc}
\hline Time in Hours & Temperature $\left({ }^{0} \mathrm{c}\right)$ & Efficiency $(\%)$ \\
\hline 10:00-11:00 & 46 & 15.17 \\
11:00-12:00 & 48 & 14.05 \\
12:00-13:00 & 50 & 12.93 \\
13:00-14:00 & 49 & 13.49 \\
14:00-15:00 & 47 & 14.61 \\
15:00-16:00 & 43 & 13.29 \\
\hline
\end{tabular}

\subsection{Effect of Angle of Tilt}

Studies shows that angle of inclination plays a greater role then orientation. For optimal orientation the PV modules are kept facing south. The angle of inclination of the panel should be such that they match the latitude of the location minus the sun's declination i.e the angle between equator and the sun. In the real time experiment conducted the module was tilted at different angle and IV and PV curve was drawn. Several researchers have suggested that upto latidude 25 degree the summer angle is 2.3 degree and winter angle is 41.4 degree. This experiment was conducted in Bhubaneshwar with latitude angle $20.2961^{\circ} \mathrm{N}$ and was found to have highest efficiency at 45 degree tilt angle i.e $16.2 \%$. 
From Figure 6 and 7 it was concluded that module shows better performance in terms of power output at 45 degree angle of inclination. In this study manual tracking method was used where as using MPPT tracker the panel adjusts its tilt angle as per the position of the sun to receive the maximum incident photon. Studies show that there are various mppt methods for tracking but in this paper only the effect of angle of tilt on the panel power output is considered. From the table IV it was also found that module tilt at 45 degree gives the maximum power and a higher fill factor.

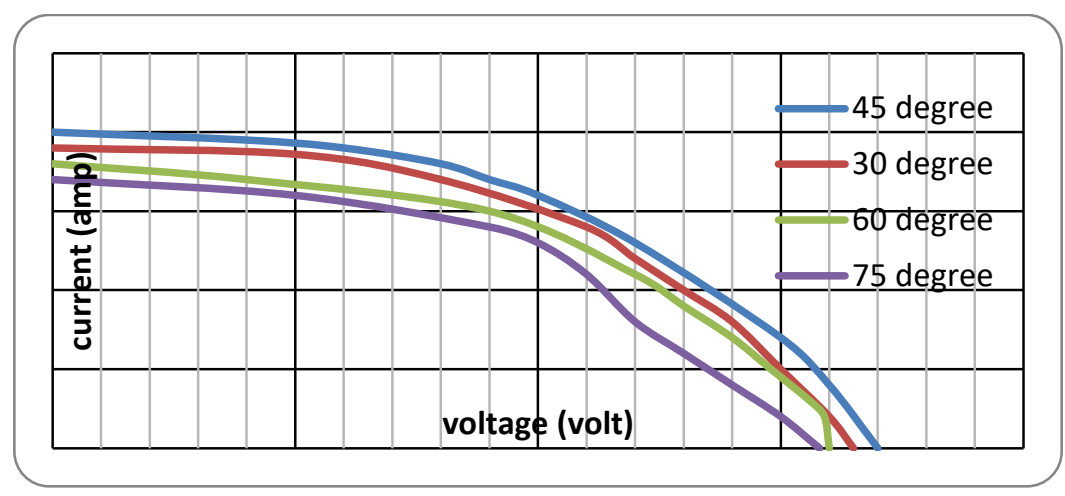

Figure 6. Shows the iv curve for various angle of inclination

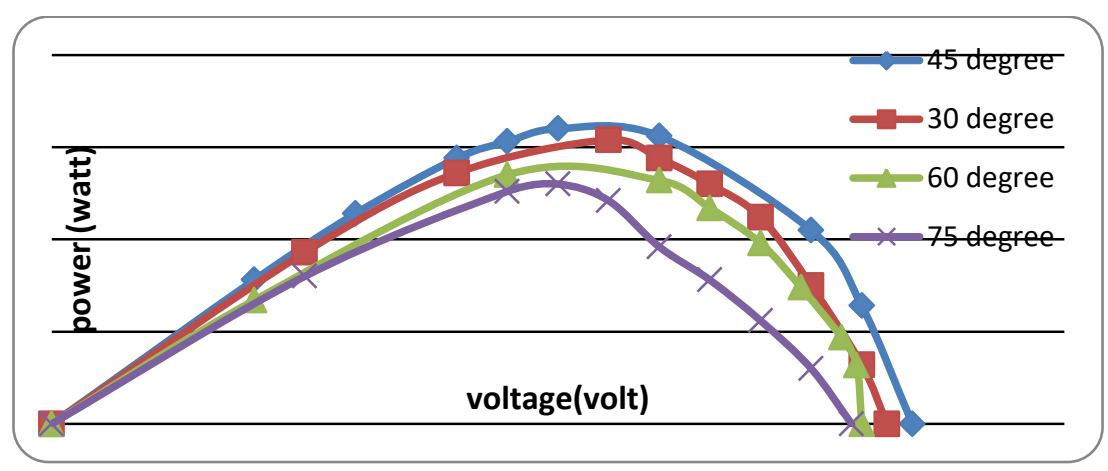

Figure 7. Shows pv curve at different angle of inclination

Table 4. Shows thevalueof Maximum power and fill factor for different titltangle

\begin{tabular}{ccc}
\hline Angle (deg) & Maximu power (watt) & Fill factor \\
\hline 30 & 15.4 & 0.62 \\
45 & 16.0 & 0.68 \\
60 & 13.5 & 0.58 \\
75 & 13 & 0.55 \\
\hline
\end{tabular}

\subsection{Effect of Soiling}

Studies show that the performance of panels over long period of time without rain events is highly reduced due to dust accumulation. Not only duration of exposure but also frequency and intensity of dust affects the PV panel's power output. Dust particles blocks the incident photons reaching the PV cell, thus reducing the useful area of the pv module. In this paper an experimental test has been conducted and was found that dust accumulation greatly affects the short circuit current where as open circuit voltage has very little effect. Even various types of dust sample have been tested to see the effect of dust on the module performance and the result was compared with that of a clean module. Motasem Saidan et al suggested that the degradation in the output efficiency of PV module on soiling condition is $6.24 \%$ on an exposure of one day [11]. Some other researchers also suggested that module efficiency decreases by $15 \%$ due to dust deposition.

From Figure 8 it is clear that depending on the type of dust there is a greater change in the cell short circuit current but very less effect in the pv open circuit voltage.Panel efficiency also varies depending on the 
types of dust present and even time of exposure considering quantity factor. From the Figure 9 pv module with clay dust shows least efficiency. It can be concluded that presesnce of dust decreases the efficiency by $33 \%$.

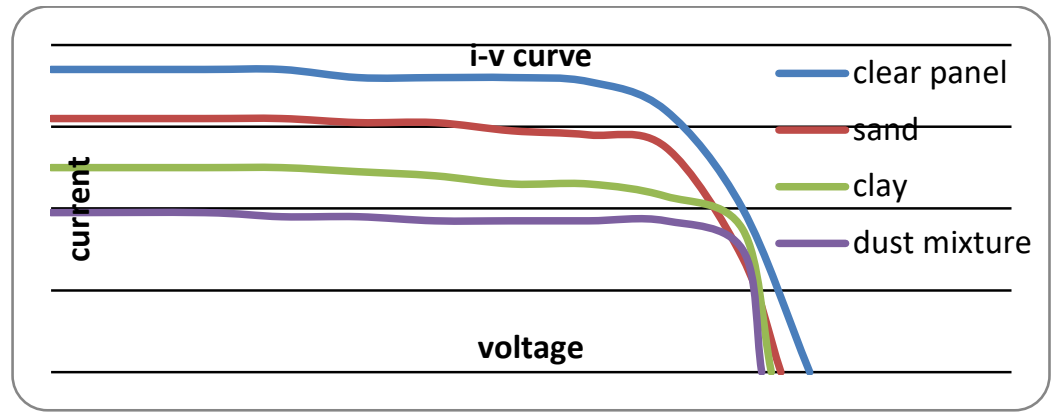

Figure 8 . Shows iv curve for different types of dust

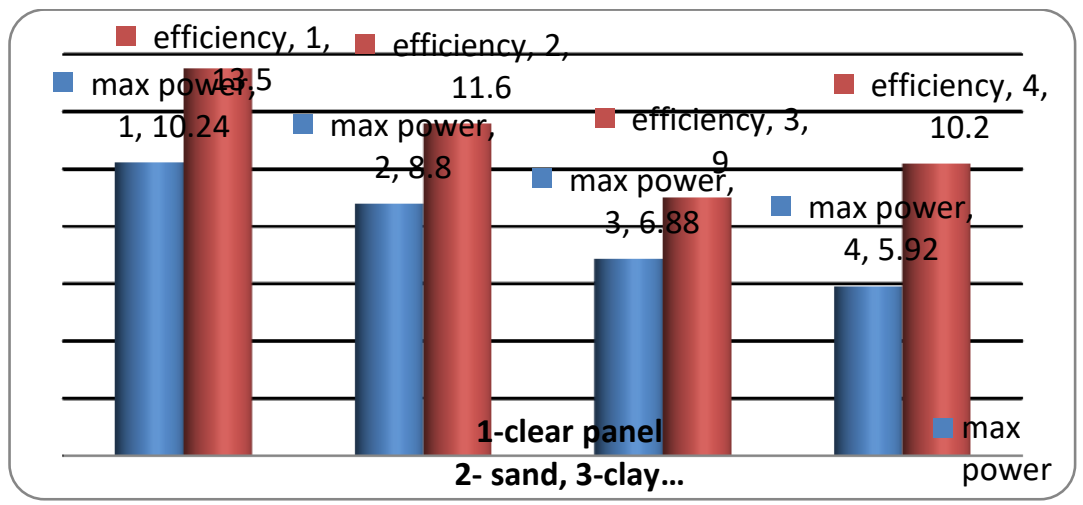

Figure 9. Maximum power and efficiency of various types of dust on pv module

\subsection{Effect of Shading}

Shade is one of the important parameter which affects the output performance of the pv module. Shading can be caused by various factors like presence of tall building, leaves falling, fog, cloud, dust particles, birds excreta etc. The shading effect can be broadly studied in two categories i.e soft shading and hard shading. It creates hotspots where temperature rises very high and can cause burning effect. Nonuniform shading causes mismatch in the current and hence power loss of the module.Sathyanarayan in his work has found out that under uniform shading condition the efficiency reduces by $0.15 \%$ for every $25 \%$ shading the panel [12]. Various studies suggest that shading is a negative factor for the performance of pv system. An experimental analysis has been carried out with different degree of shading like the module shaded for $25 \%, 50 \%$ and $75 \%$ and the result was compared with that of the clear panel without shading. For shading purpose measured cardboards were used.

Table 5 shows that with increase in the percentage shading the efficiency of the pv module decreases. Maximum power is obtained from pv module under no shade condition but with increase in percentage shading major changes in short circuit current is observed with marginal changes in open circuit voltage as shown in Figure 10 and Figure 11. From this experiment is it stated that with every $25 \%$ increase in uniform shading the efficiency of the module decreases by $3 \%$.

Table $\underline{5 . \text { Efficiency at various temperatures }}$

\begin{tabular}{cc}
\hline$\%$ Shading & Efficiency $(\%)$ \\
\hline No shading & 14.51 \\
$25 \%$ & 14.23 \\
$50 \%$ & 13.92 \\
$75 \%$ & 13.63 \\
\hline
\end{tabular}




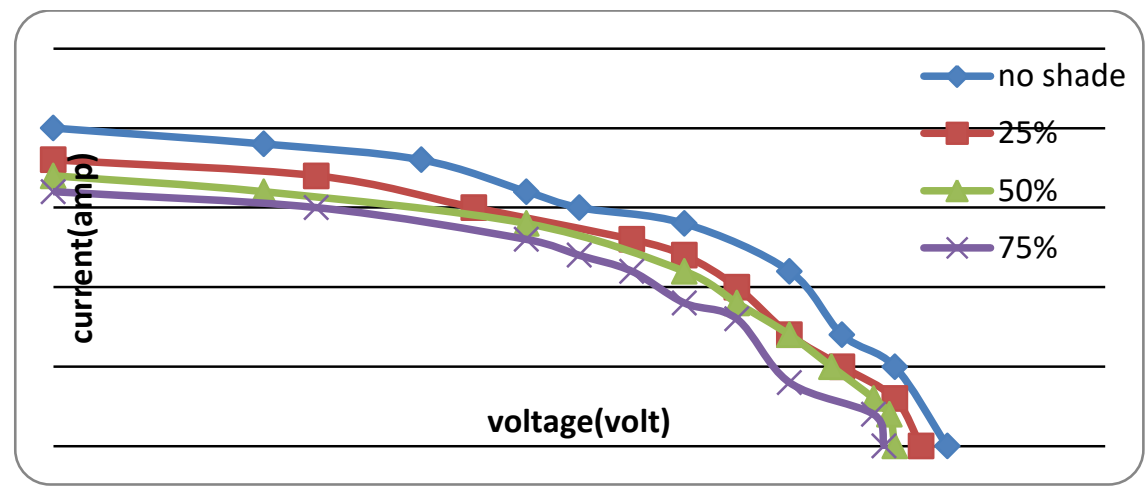

Figure 10. Shows iv curve for different shading conditions

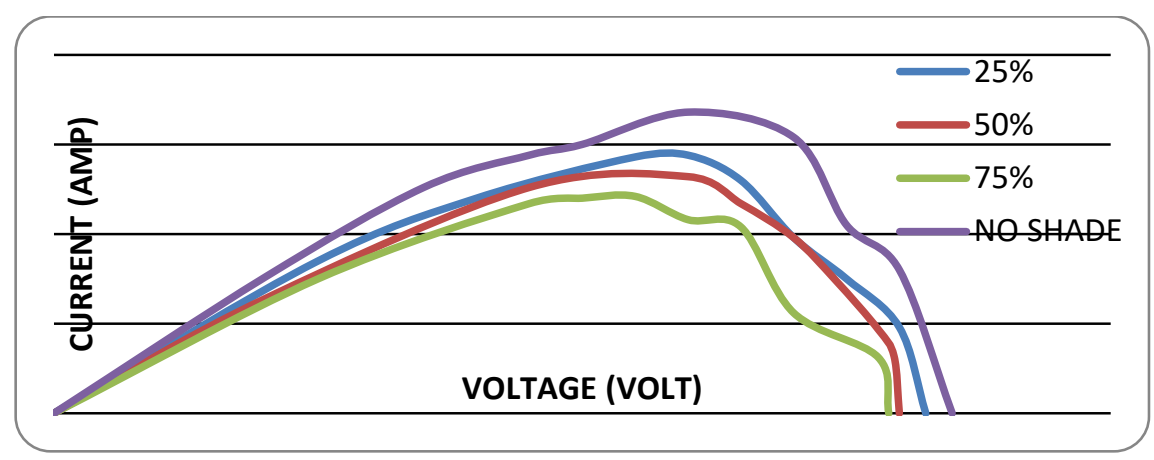

Figure 11. Shows PV curve for different shading conditions

\section{CONCLUSION}

With the increase in solar radiation striking the module maximum power increases which is experimentally obtained at around 12:00 to $1: 00 \mathrm{pm}$. But with increase in the photons reaching the module a part of this energy is converted to heat which cause rise in temperature. It is found that efficiency and power output decreases at high temperature. Water cooling or air cooling the panel at regular intervals can reduce this effect. Dust deposition does not largely affect the open circuit voltage of the PV module. At various irradiance levels open circuit voltage of dusty panel makes very small difference with that of the clear panel. The ratio of $\mathrm{V}_{\mathrm{oc}}$ (dusty) $/ \mathrm{V}_{\mathrm{oc}}$ (clean) is around $99 \%$ for various intensity of light. Accumulation of dust on the PV module greatly affects the short circuit current of the PV module. Considering various irradiance levels it is found that the difference in current $\mathrm{o} / \mathrm{p}$ increases with increase in light intensity from $220 \mathrm{watt} / \mathrm{m}^{2}$ to 880 watt $/ \mathrm{m}^{2}$. $\mathrm{I}_{\mathrm{sc}}$ for dusty panels is less than that of clear panels. A difference of $40-50 \% \mathrm{I}_{\mathrm{sc}}$ drop is observed for dusty panels. Shading is also one of the important factors which affect the module power output. From the IV and PV graph it is clearly seen that shaded modules have less power output in comparison to unshaded module. Even the module output is affected by the tilt angle and orientation. Amount of energy captured by the module can be increased by tilting the panel 15 degree steeper in winter and 15 degree less in summer with the latitude of the location. Even the output can be maximized by mechanically tracking the sun and orienting the module at various suns' position and electrically tracking and operating at maximum power point.

\section{ACKNOWLEDGEMENTS}

My sincere thanks and gratitude for school of electrical engineering, KIIT University for providing me all the testing facilities to carry out my work successfully.

\section{REFERENCES}

[1] D. J. Mbewe, et al., "A model of silicon solar cells for concentrator photovoltaic and photovoltaic thermal system design," Sol. Energy, vol/issue: 35(3), pp. 247-258, 1985. 
[2] E. H. Chahid, et al., "Effect of Measurement Factors on Photovoltaic Cell Parameters Extracting," International Journal of Electrical and Computer Engineering, IJECE, vol/issue: 7(1), pp. 50-57, 2017.

[3] G. S. Anton and D. Pachon, "Correction of the Voc vs. temperature dependence under non-uniform concentrated illumination," 17th European Photovoltaic Solar Energy Conference, Munich, Germany, pp. 156-159, 2001.

[4] R. K. Mathur, et al., "Thermal non-uniformities in concentrator solar cells," Sol. Cells 11, pp. 175-188, 1984

[5] R. W. Sanderson, et al., "The effects of nonuniform illumination and temperature profiles on silicon solar cells under concentrated sunlight," Conference record, 14th IEEE PVSC, pp. 431-436, 1980.

[6] F. Chenlo and M. Cid, "A linear concentrator photovoltaic module: analysis of non-uniform illumination and temperature effects on efficiency," Sol. Cells, vol. 20, pp. 27-39, 1987.

[7] Mousazadeh H., et al., "A review of principle and sun-tracking methods for maximizing solar systems output," Renew Sust Energy Rev, vol. 13, pp. 1800-18, 2009.

[8] Lazaroiu G. C., et al., "Comparative analysis of fixed and sun tracking low power PV systems considering energy consumption," Energy Convers Manage, vol. 92, pp. 143-8, 2015.

[9] Eke R. and Senturk A., "Performance comparison of a double-axis sun tracking versus fixed PV system," Solar Energy, vol. 86, pp. 2665-72, 2012.

[10] M. M. Musthafa, "Enhancing Photoelectric Conversion Efficiency of Solar Panel by Water Cooling," J Fundam Renewable Energy Appl, vol/issue: 5(4), pp. 1-5, 2015.

[11] M. Saidan, et al., "Experimental study on the effect of dust deposition on solar photovoltaic panels in desert environment," Elsevier, Renewable Energy, vol. 92, pp. 499-505, 2016.

[12] Sathyanarayana P., et al., "Effect of Shading on the Performance of Solar PV Panel," Energy and Power, vol/issue: 5(1A), pp. 1-4, 2015.

[13] Ismail M. S., et al., "Analysis and evaluation of various aspects of solar radiation in the Palestinian territories," Energy Convers Manage, pp. 7357-68, 2013.

[14] A. Y. Al-Hasan, "A new correlation for direct beam solar radiation received by photovoltaic panel with sand dust accumulted on its surface," Solar energy, vol/issue: 63(5), pp. 323-333, 1998.

[15] A. A Hegazy, "Effect of dust accumulation on solar transmitnce through glass coves of plate type collectors," Renewable energy, vol/issue: 22(4), pp. 525-540, 2001.

[16] A. M. El Nashar, "Effect of dust deposition on the performance of a solar desalination plantoperating in arid deset area," Solar Energy, vol/issue: 75(5), pp. 421-431, 2003.

[17] M. S. El Shobokshy and F. M. Hussain, "Degradation of photovoltaic cell performance due to dust deposition on its surface," Renewable energy, vol/issue: 3(6), pp. 585-590, 1993.

[18] R. Alik, et al., "A Study of Shading Effect on Photovoltaic Modules with Proposed P\&O Checking Algorithm," International journal of Electrical and Computer engineering, IJECE, vol/issue: 7(1), pp. 29-40, 2017

[19] J. S. Kumari and C. S. Babu, "Mathematical Modeling and Simulation of Photovoltaic Cell using Matlab-Simulink Environment," International journal of Electrical and Computer engineering, vol/issue: 2(1), pp. 26-34, 2012.

\section{BIOGRAPHIES OF AUTHORS}
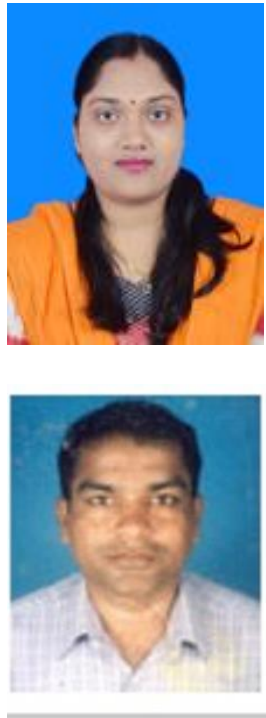

Arjyadhara Pradhan is currently working as Assistant Professor in School of Electrical Engineering, KIIT University, Bhubaneshwar, Odisha. She is continuing her Ph.D in KIIT University. She has completed her M.Tech in the area of solar pv sytem with the focus on maximum power point tracking. She was awarded with the "Institutional award" for best paper from Institution of Engineers, Odisha in the year 2012. Her broad working area is Solar Photovolatics and renewable energy systems. She has published 16 papers both in international and national journals. She has also published papers in 25 International and national conferences and among them 6 nos of IEEE conference. She has guided 3 M.Tech students and 12 B.Tech students. She is a life member of various professional bodies like SESI, IE, ISTE, ISLE, ISC.

Dr. Bhagabat Panda is working as Associate Professor in School of Electrical Engineering, KIIT University. He has completed his Ph.D from Utkal University, Vanivihar. His M.Tech is from VSSUT Burla. His working area is power quality and Hybrid energy systems. He has published a number of papers in international journal and conferences. He has produced one Ph.D Scholar and guided 20 M.Tech students. He has one ongoing project from The Institute of Engineers, Kolkata. He has organised many National seminars in the University. He has been associated with life time members of various important bodies like IEEE, SESI, IE, ISTE. 